\title{
Optimasi Produksi Biogas Dari Campuran Kotoran Sapi Dan Rumput Gajah (Pennisetum purpureum)
}

\author{
Nanda Saputra Nikolas ${ }^{1}$, G.M. Saragih ${ }^{2}$, dan Hadrah ${ }^{3 *}$ \\ Program Studi Teknik Lingkungan, Fakultas Teknik, Universitas Batanghari \\ Jalan Slamet Riyadi, Kota Jambi \\ *e-mail: hadrah.hasan@gmail.com
}

\begin{abstract}
This study aims to determine the optimization of biogas production from a mixture of cow dung and elephant grass (Pennisetum Purpureum). Cow manure and fresh elephant grass are taken directly in Teluk Singkawang Village, Sumay District, Tebo Regency, Jambi Province. This research method is the experimental method. There are 4 variations of the mixture in the digester, namely P1 (RG: $25 \%, K S: 50 \%$, water: $25 \%)$, $P 2$ (RG: 50\%, KS: 25\%, water: 25\%), P3 (KS: $75 \%$ and Water: $25 \%), P 4$ (RG: $75 \%$, and Water: 25the mixture was put into a digester from a plastic gallon with a volume of 18 liters and tightly closed. The study was conducted for 30 days. The parameters observed in this study included biogas pressure, flame test, daily temperature and initial and final $\mathrm{pH}$. The results showed that the maximum pressure in all digesters $I-V$ were as follows: $705.6(\mathrm{~N} / \mathrm{m})^{2}, 689(\mathrm{~N} / \mathrm{m})^{2}, 823.2\left(\mathrm{~N} / \mathrm{m}^{2}\right)$, and in digester IV there was no gas pressure produced. The flame test conducted showed that there was a flame on the digester I-III (with the addition of cow dung) with the flame color, yellowish blue, reddish blue, and blue. Meanwhile, Digester IV (without the addition of cow dung) does not produce a flame. while the initial pH values of all variations were in the normal range, namely $7,8,7,8$ for $P 1, P 2, P 3$ and $P 4$ respectively; while the final $p H$ was $7,6,7,4$, respectively. The average daily temperature was almost the same for all variations, namely $27.2^{\circ} \mathrm{C}, 28.26^{\circ} \mathrm{C}, 27.74{ }^{\circ} \mathrm{C}$, and $27.94{ }^{\circ} \mathrm{C}$.
\end{abstract}

Keywords: Biogas; Cow dung; Elephant grass; Digester

\section{Pendahuluan}

Sumber energi terbarukan sudah menjadi kebutuhan masyarakat Indonesia pada saat sekarang. Pasokan energi saat ini masih didominasi sumber energi fosil yang tidak dapat diperbarui yaitu gas alam, batubara dan minyak bumi. Banyaknya penggunaan sumber energi yang tidak terbarukan menyebabkan pasokan menipis dan menyebabkan masalah serius pada lingkungan berkaitan dengan efek gas rumah kaca, terutama $\mathrm{CO}_{2}$, yang merupakan faktor penyebab terjadinya (global warming) pemanasan global (Haryanto, 2014).

Sumber energi dapat dibagi menjadi 2 yaitu energi yang dapat diperbarui dan energi yang tidak dapat diperbarui. Biogas merupakan suatu alternatif sumber energi terbarukan yang dapat menjawab kebutuhan energi. Sifat biogas yang ramah lingkungan dan dapat diperbaharui merupakan kelebihan dari biogas dibandingkan dengan bahan lain (Wahyuni, 2015). Salah satu parameter yang mempengaruhi proses produksi biogas adalah tingkat pengenceran dan kandungan bahan organik di dalam digester. Indonesia memiliki potensi biomassa yang melimpah untuk dijadikan bahan dasar pembuatan biogas. Salah satu biomassa yang dapat dijadikan sumber energi alternatif biogas yaitu campuran kotoran sapi dan rumput gajah (Pennisetum purpureum).

Menurut Budiyanto (2011), satu ekor sapi dapat menghasilkan 7-9 kilogram kotoran dalam satu hari. Salah satu wilayah yang memiliki potensi besar adanya kotoran sapi dan rumput gajah adalah Desa Teluk Singkawang yang berada di Kabupaten Tebo, Provinsi Jambi. Namun, saat ini belum adanya pemanfaatan maupun pengolahan limbah kotoran sapi dari hasil kegiatan perternakan masyarakat. Berdasarkan tinjauan lapangan yang dilakukan, sapi hanya bebas berkeliaran di lapangan dan tidak dimasukkan dalam kandang yang telah disediakan. Hal ini menyebabkan banyak kotoran sapi yang berserakan di sekitar lingkungan Desa Teluk Singkawang. Saat ini, jumlah ternak sapi milik masyarakat yang terhitung adalah 160 ekor, sehingga limbah kotoran sapi yang dihasilkan dalam satu hari sebanyak $1.120 \mathrm{~kg}-1.140 \mathrm{~kg}$. Padahal dengan kondisi jumlah ternak sapi sebanyak itu berpotensi menghasilkan energi alternatif. Dampak negatif yang timbul di lingkungan desa adalah tercemarnya lingkungan oleh bau kotoran sapi.

\section{Metode Penelitian}

Metode penelitian yang digunakan dalam penelitian ini adalah metode eksperimen. Meteode eksperimen adalah penelitian yang digunakan untuk pengujian hipotesa dalam bentuk hubungan sebab akibat diantara variabel yang diteliti. Adapun parameter yang di ukur adalah tekanan biogas pada digester, $\mathrm{pH}$ dan temperatur serta melakukan uji nyala dengan melihat warna nyala api dan lama waktu nyala api.

\subsection{Lokasi dan Waktu Penelitian}

Penelitian ini dilaksanakan pada tanggal 21 Juli - 21 Agustus 2020 di Desa Teluk Singkawang, Kecamatan Sumay, Kabupaten Tebo, Provinsi Jambi.

\subsection{Bahan dan Alat Penelitian}

Bahan utama yang digunakan dalam proses pembuatan biogas adalah kotoran sapi sebagai starter dan rumput gajah sebagai campuran variasi pembuatan biogas serta tambahan air untuk pengenceran kotoran sapi agar mudah untuk melakukan dekomposisi terhadap rumput gajah.

Alat yang digunakan adalah sebagai berikut:

1. 4 buah galon bekas bervolume 19 liter

2. Ban mobil bekas 4 buah

3. Selang penghubung galon ke ban 6 meter

4. 4 buah kran gas berdiameter $1 / 4$ inci

5. 8 buah tutup pipa $1 / 2$ inci

6. Baut dan mur

7. Sambungan Y 4 buah

8. 24 buah klemp pengunci 
9. 2 buah ember

10. Pipa panjang 3 meter

11. Corong minyak

12. Lem tembak dan solder

13. Korek api

14. Alat ukur tekanan berupa manometer U sederhana

\subsection{Skema Alat Peneltian}

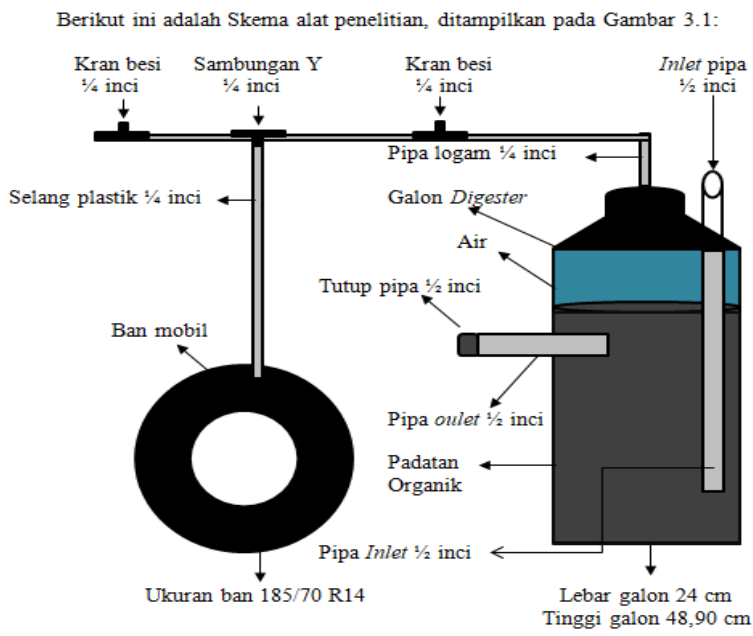

Gambar 3.1 Skema alat penelitian

\subsection{Variasi Campuran}

Rumput gajah dicacah dengan panjang maksimum 5 $\mathrm{cm}$, kemudian dicampur dengan kotoran sapi yang telah diencerkan terlebih dahulu dengan air. Komposisi antara kotoran sapi dan rumput gajah ada 4 variasi campuran yaitu dengan penambahan air konstan $25 \%$. Semua variasi campuran ditampilkan pada tabel berikut:

Tabel 2.1 Variasi campuran bahan pada Digester

\begin{tabular}{ccccc}
\hline \multirow{2}{*}{ Digesser } & \multicolumn{2}{c}{ Komposisi Padatan } & \multirow{2}{*}{ Air } & $\begin{array}{c}\text { Volume Total } \\
\text { (Liter) }\end{array}$ \\
\cline { 2 - 3 } & Rumput gajah & Kotoran Sapi & & (25\% \\
\hline I & $25 \%$ & $50 \%$ & $25 \%$ & 18 \\
II & $50 \%$ & $25 \%$ & $25 \%$ & 18 \\
III & $0 \%$ & $75 \%$ & $25 \%$ & 18 \\
IV & $75 \%$ & $0 \%$ & $25 \%$ & 18 \\
\hline
\end{tabular}

\subsection{Parameter yang Diamati}

Adapun parameter yang diamati adalah:

1. Tekanan Biogas

Perubahan tekanan biogas diamati setiap 24 jam sesuai dengan perkiraan waktu selesainya persiapan pengisian bahan ke dalam alat penghasil biogas. Hal ini dilakukan dengan mencatat angka/nilai yang di ukur dari tinggi selisih permukaan air pada manometer $U$.

2. Uji Nyala

Uji nyala dilakukan setiap satu minggu ( 7 x 24 jam) untuk melihat ada tidaknya nyala api dari semburan biogas. Pelaksanaan uji nyala dilakukan secara kualitatif yaitu dengan melihat perubahan besar nyala api pada korek api setelah dihembus dengan gas yang keluar dari kran selang serta warna nyala api. Uji nyala api berfungsi sebagai indikator kandungan gas metan pada biogas.

3. Derajat keasaman $(\mathrm{pH})$

Derajat keasaman $(\mathrm{pH})$ merupakan faktor penting pada proses fermentasi anaerob. Derajat keasaman digester harus dijaga pada nilai $6,8 \uparrow 7,2$. Pengukuran $\mathrm{pH}$ dilakukan pada awal proses pembuatan variasi campuran digester dan pada akhir penelitian. Hal ini diharapkan dapat menemukan perbandingan nilai $\mathrm{pH}$ pada awal dan akhir penelitian produksi biogas dari campuran kotoran sapi dan rumput gajah.

4. Temperatur

Temperatur/suhu adalah parameter proses yang memegang peranan sangat penting. Proses fermentasi anaerob sangat peka terhadap perubahan suhu. Pengukuran suhu dilakukan setiap hari untuk melihat perubahan suhu pada digester mulai dari hari pertama sampai hari ke-30. Pengukuran suhu dilakukan menggunakan alat ukur suhu yaitu termometer suhu ruang.

\section{Hasil dan Pembahasan}

\subsection{Tekanan pada Digester 1}

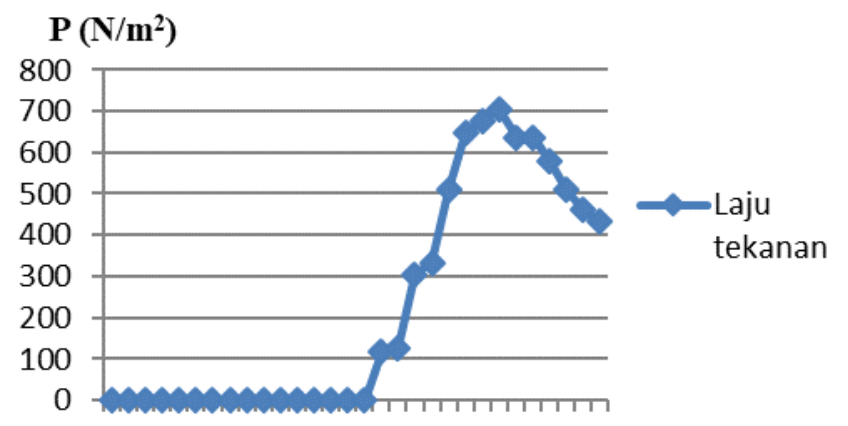

$\begin{array}{llllllllll}1 & 4 & 7 & 10 & 13 & 16 & 19 & 22 & 25 & 28\end{array}$

t (hari)

Gambar 3.1 Grafik Tekanan pada Digester I

Adanya tekanan setelah dua minggu menunjukkan bahwa biogas telah dihasilkan pada digester ini. Log phase diasumsikan mulai terjadi sejak hari ke-16, dimana peningkatan tekanan pada digester mengalami kenaikan yang cukup signifikan hingga hari ke-24. Kenaikan tertinggi tercapai pada hari ke-24 dengan tekanan 705,6 $\left(\mathrm{N} / \mathrm{m}^{2}\right)$, pada keadaan ini merupakan nilai terbaik untuk produksi biogas didalam digester. Setelah fase ini berakhir barulah mulai terjadi stationary phase pada hari ke-25 dan hari ke-26, tekanan gas terus mengalami penurunan tajam menuju death phase sampai hari ke-30 dengan tekanan 431,2 (N/m²). Hal ini terjadi karena proses fermentasi sudah berkurang diakibatkan substrat sudah terurai sehingga pertumbuhan dan aktifitas bakteri mengalami penurunan dan bakteri akan mati karena tidak adanya makanan lagi yang tersedia di dalam digester. 


\subsection{Tekanan pada digester II}

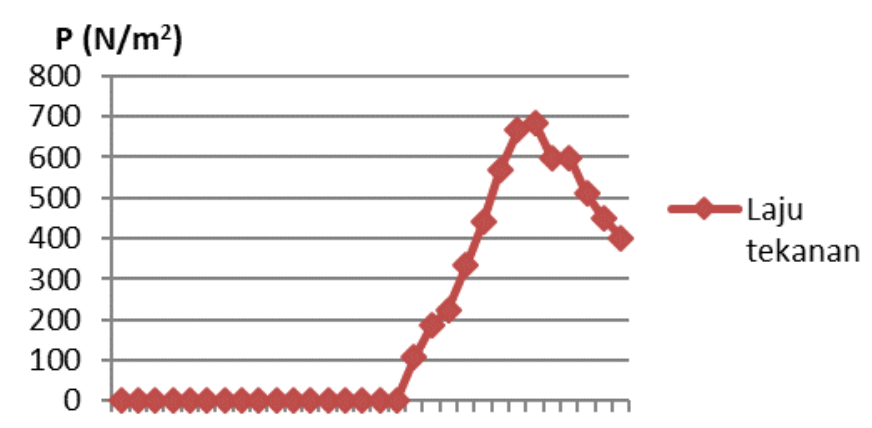

$144 \quad 7 \quad 1013161922 \quad 2528$

t (hari)

Gambar 3.2 Grafik tekanan pada digester II

Berdasarkan grafik diatas tekanan gas pada digester setelah 2 minggu lebih mulai mengalami perubahan. Log phase diasumsikan mulai terjadi sejak hari ke-18, dimana peningkatan tekanan pada digester mengalami kenaikan yang cukup signifikan. Kenaikan tertinggi tercapai pada hari ke-25 dengan tekanan $686\left(\mathrm{~N} / \mathrm{m}^{2}\right)$. Setelah itu mulai terjadi stationary phase pada hari ke-26 dan hari ke-27, tekanan gas terus mengalami penurunan tajam menuju death phase sampai hari ke-30 dengan tekanan 401,8 $\left(\mathrm{N} / \mathrm{m}^{2}\right)$. Hal ini terjadi karena proses fermentasi sudah berkurang diakibatkan substrat sudah terurai sehungga pertumbuhan dan aktifitas bakteri mengalami penurunan dan bakteri akan mati karena tidak adanya makanan lagi yang tersedia di dalam digester. Faktor lainnya adalah campuran variasi campuran rumput gajah sebanyak $50 \%$ menjadi salah satu penghambat produksi biogas optimal dan dapat pula mempengaruhi keadaan temperatur dan nilai $\mathrm{pH}$ didalam digester. Terlalu banyak variasi campuran membuat tingkat pengenceran didalam digester menjadi terhambat. Hal ini dikarenakan rumput gajah memerlukan waktu yang cukup lama untuk terurai, sehingga hal ini dapat menghambat proses fermentasi didalam digester.

\subsection{Tekanan pada digester III}

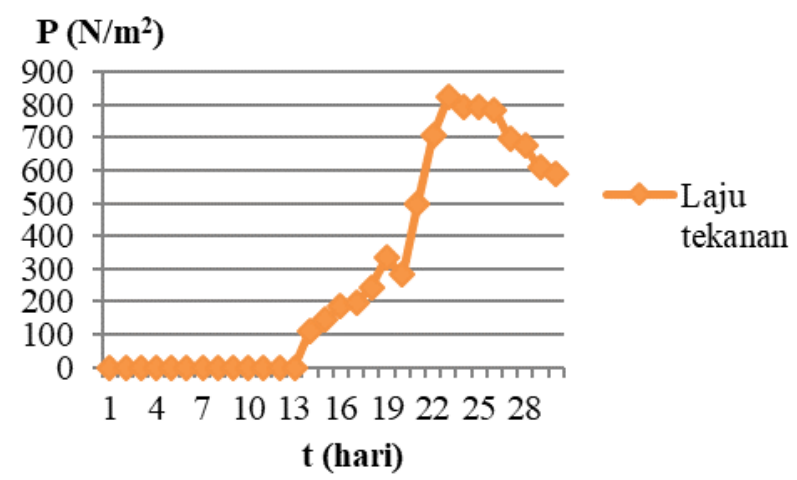

Gambar 3.3 Grafik tekanan pada digester III

Berdasarkan grafik diatas menunjukkan adanya tekanan setelah dua minggu, terlihat mulai perubahan signifikan pada ban penampung gas. Log phase diasumsikan mulai terjadi sejak hari ke-14, dimana peningkatan tekanan pada digester mengalami kenaikan yang cukup signifikan hingga hari ke-23.
Kenaikan tertinggi tercapai pada hari ke-23 dengan tekanan $823,2\left(\mathrm{~N} / \mathrm{m}^{2}\right)$. Pada keadaan ini merupakan nilai terbaik dalam produksi gas metan karena pertumbuhan bakteri metan sedang meningkat sehingga produksi gas menjadi lebih banyak. Setelah itu mulai terjadi stationary phase pada hari ke-24 dan hari ke-25, tekanan gas terus mengalami penurunan tajam menuju death phase sampai hari ke-30 dengan tekanan 588 $\left(\mathrm{N} / \mathrm{m}^{2}\right)$. Hal ini terjadi karena proses fermentasi sudah berkurang diakibatkan substrat sudah terurai sehingga pertumbuhan dan aktifitas bakteri mengalami penurunan dan bakteri akan mati karena tidak adanya makanan lagi yang tersedia di dalam digester.

\subsection{Tekanan pada digester IV}

Pada digester ini tidak terdapat adanya tekanan gas yang dihasilkan mulai dari hari pertama sampai hari ke-30. Salah satu faktor penyebab tidak adanya tekanan gas dipengaruhi proses fermentasi yang tidak berjalan baik dan digester tidak menggunakan campuran kotoran sapi sebagai starter yang menyebabkan keadaan $\mathrm{pH}$ rendah sehingga bakteri metanogen tidak bekerja dengan baik karena berada dibawah optimum keadaan derajat keasaman yang baik dan faktor lain adalah perlakuan variasi campuran rumput gajah $75 \%$ sehingga menyebabakan semakin rendah tingkat pengenceran maka semakin tinggi nilai derajat keasaman pada substrat awal dan akhir pengamatan. Diasumsikan log phase kemungkinan terjadi setelah hari ke-30 dan berlanjut pada fase-fase berikutnya. Perlunya waktu tambahan untuk penelitian digester biogas yang memiliki variasi campuran rumput gajah diatas $50 \%$, dikarenakan rumput gajah perlu perlakuan khusus yakni harus di fermentasikan terlebih dahulu sehingga pada saat dijadikan variasi campuran pembuatan biogas dari kotoran sapi akan cepat terurai dan menghasilkan tingkat pengenceran yang baik dan membuat keadaan temperatur dan $\mathrm{pH}$ menjadi stabil sehingga bakteri metan akan memproduksi gas metan dengan kualitas yang lebih baik serta lebih banyak.

\subsection{Tekanan pada semua digester}

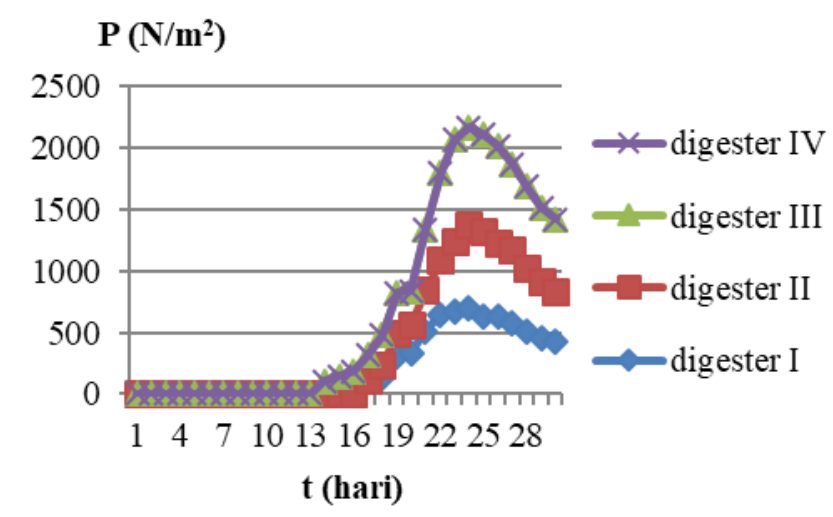

Gambar 3.4 Grafik tekanan pada seluruh digester

Berdasarkan grafik yang telah disajikan diatas tekanan tertinggi diperoleh pada digester III yaitu 823,2 (N/m²). Bahan baku biogas pada digester ini adalah kotoran sapi dan air dengan perbandingan $75 \%: 25 \%$. Sedangkan pada digester I dan II, tekanan tertinggi secara berturut-turut adalah 705,6 $\left(\mathrm{N} / \mathrm{m}^{2}\right)$ dan $686\left(\mathrm{~N} / \mathrm{m}^{2}\right)$. berdasarkan pengukuran tekanan, maka dapat disimpulkan semakin besar jumlah kotoran sapi 
yang digunakan maka semakin tinggi tekanan dan tingkat optimasi biogas yang dihasilkan pada digester. Hal ini dimungkinkan karena kotoran sapi merupakan substrat yang paling baik sebagai sumber biogas, karena banyak mengandung bakteri gas metana. Bakteri tersebut dapat mempercepat proses fermentasi sehingga proses pembentukan biogas menjadi lebih cepat.

\subsection{Uji nyala api}

Tekanan masing-masing digester I-IV berturut-turut adalah sebagai berikut: 705,6 $\left(\mathrm{N} / \mathrm{m}^{2}\right), 689\left(\mathrm{~N} / \mathrm{m}^{2}\right), 823,2$ $\left(\mathrm{N} / \mathrm{m}^{2}\right)$, dan digester IV tidak ada tekanan gas yang dihasilkan. Adapun hasil uji nyala api yang dilakukan menunjukkan adanya nyala api pada digester I-III (dengan penambahan kotoran sapi) dengan warna nyala api, biru kekuningan, biru kemerahan, dan biru. Sedangkan digester IV (tanpa penambahan kotoran sapi) tidak menghasilkan nyala api.

\subsection{Derajat Keasaman (pH)}

Derajat keasaman merupakan faktor penting pada proses fermentasi anaerob. Derajat keasaman dalam digester harus dijaga pada nilai $\mathrm{pH} 6,8 \uparrow 7,2$. Derajat keasaman optimal pada slurry bertujuan agar proses hidrolisis pada substrat berlangsung optimal dan dapat mempengaruhi proses selanjutnya yaitu asidifikasi dan metanasi. Bakteri akan bekerja aktif pada nilai $\mathrm{pH}$ yang spesifik dan menunjukkan aktivitas maksimal pada nilai $\mathrm{pH}$ optimal. Derajat keasaman optimal yang dibutuhkan bakteri asidogenik yaitu 5 - 6,5, sedangkan $\mathrm{pH}$ optimal untuk bakteri metanogenesis yaitu diatas 6,5. Apabila Nilai $\mathrm{pH}$ berada di bawah 6,5 maka aktifitas bakteri metanogen akan menurun dan apabila nilai $\mathrm{pH}$ berada di bawah 5,0, maka fermentasi akan terhenti dan jika nilai $\mathrm{pH}$ tinggi dari 8,5 akan terjadi pengaruh yang negatif pada bakteri metanogen, sehingga akan mempengaruhi laju pembentukan biogas dalam digester.

\section{Derajat Keasaman (pH) pada Seluruh Digester}

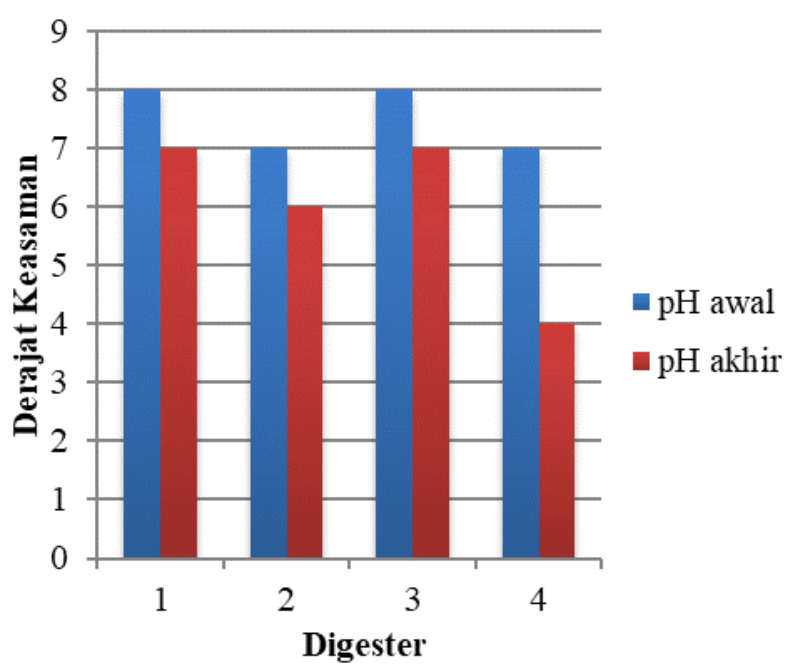

Gambar 3.5 Grafik pH pada seluruh digester

Dari hasil gabungan keseluruhan $\mathrm{pH}$ pada digester 1-4 terjadi penurunan nilai $\mathrm{pH}$ yang cukup signifikan pada digester 4 yang menyebakan bakteri metanogen tidak dapat bekerja dengan baik menghasilkan gas metana. Faktor perlakuan variasi campuran juga menjadi salah satu faktor terjadinya penurunan $\mathrm{pH}$, seperti diketahui derajat keasaamn juga memegang peranan penting dalam proses fermentasi dan pembentukan gas metan dalam proses pembuatan biogas dari kotoran sapi.

Pada digester I-III nilai $\mathrm{pH}$ berada dalam keadaan netral dan baik untuk aktifitas bakteri metanogen sehingga bakteri ini bekerja dengan baik dan menghasilkan gas metana yang cukup tinggi, hal ini sesuai dengan teori (Sharifani dan Soewondo, 2009) bahwa bakteri akan bekerja pada $\mathrm{pH}$ yang spesifik dan menunjukkan aktivitas maksimal pada $\mathrm{pH}$ optimal.

\subsection{Temperatur Gas}

Suhu adalah parameter proses yang memegang peranan sangat penting. Proses fermentasi anaerob sangat peka terhadap perubahan suhu. Produksi biogas akan menurun secara cepat akibat perubahan temperatur yang mendadak dalam reaktor. Bakteri metanogenik berkembang lambat dan sensitif terhadap perubahan mendadak pada kondisi-kondisi fisik dan kimiawi. Bakteri anaerobik dapat bertahan dari suhu beku sampai dengan suhu $70{ }^{\circ} \mathrm{C}$, namun bekerja optimum pada suhu mesofilik $\left(25-40{ }^{\circ} \mathrm{C}\right.$, dengan suhu optimum $\left.35^{\circ} \mathrm{C}\right)$ atau suhu termofilik $\left(50-65{ }^{\circ} \mathrm{C}\right.$, dengan suhu optimum $<55$ $\left.{ }^{\circ} \mathrm{C}\right)$.

\section{Temperatur Gas pada Digester I-IV}

\section{Suhu ${ }^{\circ} \mathrm{C}$}

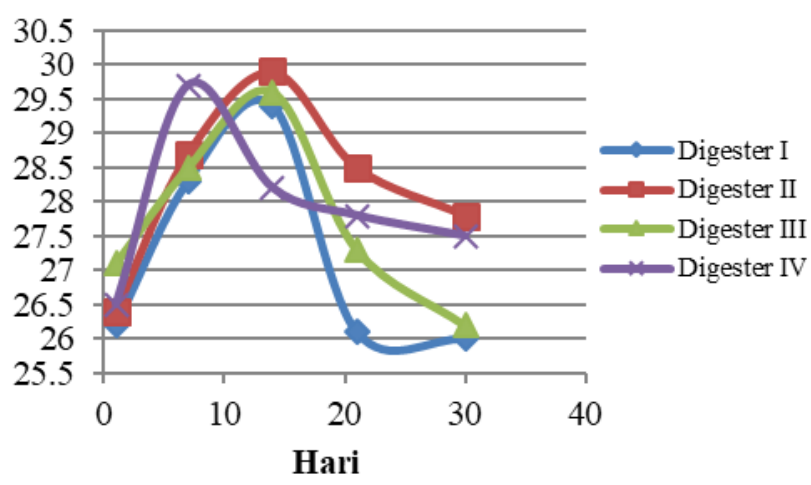

Gambar 3.6 Grafik Temperatur Seluruh Digester

Suhu pada masing-masing digester I-IV mulai naik pada 7 hari pertama, suhu yang tinggi di dalam digester disebabkan adanya aktivitas anaerob oleh bakteri yang menyebabkan peningkatan suhu di dalam digester. Pada hari ke 14 dan 21 terjadi peningkatan suhu yang cukup tinggi tetapi masih berada didalam keadaan suhu mesofilik antara suhu $25^{\circ} \mathrm{C}$ dan $30{ }^{\circ} \mathrm{C}$. Dalam keadaan suhu mesofilik bakeri metanogen bekerja dengan baik dan proses fermentasi berjalan dengan baik sehingga akan menghasilkan tekanan gas metana serta $\mathrm{pH}$ yang netral pula. Setelah hari ke 21 suhu pada masing-masing digester mulai mengalami penurunan yang cukup signifikan sampai hari ke-30. Selama proses pengukuran tekanan suhu dari hari ke-1 sampai hari ke-30, suhu didalam digester tetap berada dalam keadaan suhu mesofilik dan cocok untuk perkembangan bakteri metanogen untuk menghasilkan gas metana. Temperatur optimal menjadi salah satu syarat agar proses anaerob dapat terjadi dengan cepat dan biogas yang dihasilkan berkualitas baik. 


\subsection{Optimasi Biogas}

Optimasi biogas dari variasi campuran bahan baku digester menunjukkan hasil bahwa komposisi digester yang dicampur dengan rumput gajah menghasilkan biogas yang kurang optimal dimana dapat dilihat dari warna nyala api berwarna biru kekuningan dan biru kemerahan, warna nyala api tersebut berindikasikan bahwa kandungan gas yang dihasilkan memiliki kandungan gas metan yang masih dibawah rasio $\mathrm{CN}_{4} 60 \%$ serta bercampur dengan gas $\mathrm{CO}_{2}$ menyebabkan warna nyala api tidak berwarna biru. Berbeda dengan digester tanpa variasi campuran yaitu hanya kotoran sapi dan air yang menghasilkan nyala api biru, hal ini berindikasikan bahwa kandungan gas metan pada digester yang tanpa variasi campuran memiliki kandugan gas metan yang tinggi yaitu diatas $60 \%$ dari rasio $\mathrm{CN}_{4}$.

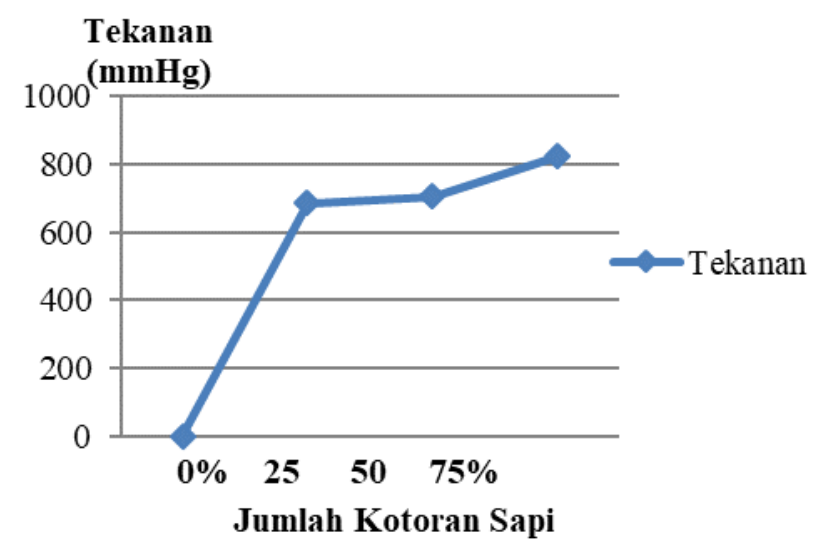

Gambar 3.7 Grafik Tekanan Pengaruh Tambahan Kotoran Sapi

Dari grafik diatas, optimasi produksi biogas sangat berpengaruh pada jumlah kotoran sapi yang digunakan, jika dengan penambahan jumlah kotoran sapi sebanyak $25 \%$ maka akan menghasilkan peningkatan tekanan sebesar $0,09 \mathrm{mmHg}$ pada setiap digester. Dan apabila produksi biogas dengan variasi campuran kotoran sapi dan rumput gajah serta air belum menunjukkan hasil yang optimal sehingga belum dapat memenuhi dan menjadi pengganti dari ketergantungan masyarakat terhadap LPG. Akan tetapi jika dilakukan perubahan variasi campuran komposisi dari biogas diharapkan akan mendapatkan hasil biogas yang lebih optimal sehingga dapat dijadikan energi alternatif pengganti LPG.

\section{Kesimpulan dan Saran}

Setelah melakukan eksperimen pembuatan biogas dari campuran kotoran sapi dan rumput gajah ada beberapa kesimpulan yang diperoleh penulis yaitu :

1. Tekanan masing-masing digester I-IV berturut-turut adalah sebagai berikut: 705,6 (N/m²), $689\left(\mathrm{~N} / \mathrm{m}^{2}\right), 823,2\left(\mathrm{~N} / \mathrm{m}^{2}\right)$, dan digester IV tidak ada tekanan gas yang dihasilkan. Adapun hasil uji nyala api yang dilakukan menunjukkan adanya nyala api pada digester I-III (dengan penambahan kotoran sapi) dengan warna nyala api, biru kekuningan, biru kemerahan, dan biru. Sedangkan digester IV (tanpa penambahan kotoran sapi) tidak menghasilkan nyala api.

2. Nilai $\mathrm{pH}$ awal yang dihasilkan pada digester I, II, III dan IV berada pada kisaran normal yaitu, 8, 7, 8, 7. Sedangkan $\mathrm{pH}$ akhir yang dihasilkan pada digester I, II, III dan IV yaitu, $7,6,7,4$. Temperatur/suhu rata-rata pada setiap digester berturut-turut yaitu: $27,2^{\circ} \mathrm{C}, 28,26{ }^{\circ} \mathrm{C}, 27,74{ }^{\circ} \mathrm{C}$, $27,94{ }^{\circ} \mathrm{C}$. Semua temperatur yang dihasilkan masih didalam keadaan temperatur mesofilik yang baik untuk bakteri metanogen.

3. Optimasi produksi biogas menggunakan kotoran sapi menunjukkan bahwa semakin tinggi jumlah kotoran sapi maka semakin tinggi produksi biogas yang dihasilkan. Berdasarkan eksperimen yang dilakukan, penambahan kotoran sejumlah 25\% akan menghasilkan tekanan digester sebesar $0,09 \mathrm{mmHg}$

\section{Daftar Pustaka}

Afrian. C., dkk. (2017). Produksi Biogas Dari Campuran Kotoran Sapi Dengan Rumput Gajah (Pennisetum Purpureum). Jurnal Teknik Pertanian Lampung-Vol. 6, No. 1: 21-32

Ramdiana. (2017). Pengaruh Variasi Komposisi Pada Campuran Limbah Cair Aren dan Kotoran Sapi Terhadap Produksi Biogas. Eksergi, Vol 14, No. 2. 2017

Ni'mah, L. (2014). Biogas From Solid Waste Of Tofu Production And Cow Manure Mixture: Composition Effect. Chemica Volume 1, Nomor 1, Juni 2014, 1-9 ISSN : 2355-8776.

Kurniawan, W. dkk (2016). Uji Potensi Biogas dari Limbah Jeroan Ikan Patin (Pangasius $s p$ ) dan Campuran Kiambang (Salvinia molesta) secara Anaerob Batch. Jurnal Teknologi Hasil Perikanan. Vol. 5, No.1: 43-51.

Budiyanto, Krisno. 2011. "Tipologi Pendayagunaan Kotoran Sapi dalam Upaya Mendukung Pertanian Organik Sumbersari Kecamatan Poncokusumo Kabupaten Malang". Jurnal GAMMA 7(1) 42-49

Hariyanto, A. 2014. Energi Terbarukan. Bandar Lampung. Bab V : 195-246

Nuntiya, P., A. Nopharatana, and W. Songkasiri. 2009. BioMethane Potential of Biological Solid Materials and Agricultural Wastes. Asian Journal on Energy and Environment. Vol 10 (1) : 19-27

Fairuz, A. (2015). Pengaruh Penambahan ampas kelapa dan kulit pisang terhadap produksi biogas dari kotoran sapi. [Tesis]. Bandar Lampung: Fakultas Teknik Pertanian, Universitas Lampung

Afrian, Chandra. (2017). Produksi Biogas Dari Campuran Kotoran Sapi Dengan Rumput Gajah (Pennisetum Purpureum). Tugas Akhir Skripsi. Teknik Pertanian Fakultas Pertanian Universitas Lampung.

Lazuardi, I,. (2008). "Rancangan Bangun Alat Penghasil Biogas Model Terapung". Tugas Akhir Skripsi. Fakultas Pertanian, Universitas Sumatera Utara.

Harsono, 2013. "Aplikasi biogas sistem jaringan dari kotoran sapi di desa bumijaya kec, anak tuha lampung tengah sebagai energi alternatif yang efektif". Tugas Akhir Skripsi . Jurusan Teknik Mesin, Universitas Lampung.

Wahyuni, S. 2013. Biogas Energi Alternatif Pengganti BBM, Gas, Listrik. PT. Agro Media Pustaka. Jakarta Selatan. $117 \mathrm{hlm}$.

Deublein, D,. and A Steinhauser. 2008. Biogas From Waste and Renewable Resource. Wiley-VCH Verlag GmbH \& Co.KgaA. Weinheim. $443 \mathrm{hlm}$. 
Nanda Saputra Nikolas, G.M. Saragih dan Hadrah, Optimasi Produksi Biogas Dari Campuran Kotoran Sapi Dan Rumput Gajah (Pennisetum purpureum)

Firdaus, U.I., (2009). “Biogas Energi yang Baik Untuk Dikembangkan di Lampung”.

http://harsono7223.blogspot.com/2012/12/biogas-di Lampung.html.

http://www.klikteknik.com/blog/fungsi-manometer-dan-jenisjenisnya.html 